\title{
INFLUENCE OF GENDER ON THE ONSET AND DURATION OF ROCURONIUM-INDUCED NEUROMUSCULAR BLOCK
}

\author{
Milan Adamus*, Jirina Koutna, Tomas Gabrhelik, Mariana Hubackova, Eva Janaskova
}

Department of Anaesthesiology and Intensive Care Medicine, Teaching Hospital and Faculty of Medicine and Dentistry, Palacky University, Olomouc, Czech Republic

*e-mail:milan.adamus@seznam.cz

Received: April 14, 2007; Accepted: September 9, 2007

Key words: Neuromuscular block/Gender/Rocuronium/Clinical duration/Onset time/Recovery index

Aims: To assess the influence of gender on the course of rocuronium-induced neuromuscular block following a single bolus dose of $2 \times \mathrm{ED}_{95}\left(0.6 \mathrm{mg} \mathrm{kg}^{-1}\right)$.

Methods: Following the ethics committee approval and informed consent, 245 patients (121 men, 124 women) scheduled for elective general surgery under TIVA with muscle relaxation were studied. After rocuronium $0.6 \mathrm{mg} \mathrm{kg}^{-1}$, the onset time for maximal depression of $\mathrm{T}_{1}$, clinical duration until $25 \%$ recovery and recovery index $\left(\mathrm{T}_{1}\right.$ from 25 to $75 \%$ ) were determined with TOF-Watch ${ }^{\circledR}$ SX accelerometric monitor. The data for male and female groups were compared with appropriate statistical tests (Student's unpaired t-test, Mann-Whitney Rank Sum Test and Fisher's exact test).

Results: Men were significantly larger $(p<0.001)$ and heavier $(p<0.05)$ than women, but the body mass index was comparable $(n s)$. The onset time was shorter in females [92.5 (SD 14.2) vs. 104.7 (12.2) s, $p<0.0001$ ]. Clinical duration was increased in females [43.1 (7.9) vs. 31.3 (5.5) min; $p<0.0001$ ], while the recovery index was identical in both groups [14.7 (5.0) $\mathrm{min}$ in females and 14.8 (4.0) $\mathrm{min}$ in males; $n s]$.

Conclusions: Women are more sensitive than men to the dose $0.6 \mathrm{mg} \mathrm{kg}^{-1}$ of rocuronium. Under the study conditions described, the onset time was shortened and the clinical duration increased in female patients. This suggests that the routine dose of rocuronium should be reduced in women.

\section{INTRODUCTION}

Traditionally, body weight (BW), body surface area (BSA) and/or body mass index (BMI) are the usual variables used to calculate the dose of a drug. However, there is increasing evidence for gender differences in the pharmacokinetics and pharmacodynamics of anaesthetic and neuromuscular blocking agents ${ }^{1}$. Females may be more susceptible to the effect of a drug, while requiring larger doses of another one to achieve the same effect as in males.

Rocuronium (ROC) is a modern aminosteroid neuromuscular blocking agent (NMBA) with intermediate duration of action. Introduced into clinical practice in 1992 , it is frequently used during general anaesthesia allover the world today. ROC is a non-depolarizer with the fastest onset (45-60 s) and clinical duration of approximately 30-50 minutes ${ }^{2}$.

The purpose of this study was to investigate whether and how gender influences the course of rocuronium-induced neuromuscular block following single bolus dose of $2 \times \mathrm{ED}_{95}\left(0.6 \mathrm{mg} \mathrm{kg}^{-1}\right)$.

\section{MATERIAL AND METHODS}

After obtaining local Ethics Committee approval and informed consent, 250 adult patients, scheduled for elec- tive general surgery under total intravenous anaesthesia (TIVA) with tracheal intubation, muscle relaxation and mechanical ventilation, were studied. Exclusion criteria were ASA physical status III or more, age under 18 and over 65 years and obesity (BMI $>30 \mathrm{~kg} \mathrm{~m}^{-2}$ ). Patients using medication known to interfere with NMBAs (anticonvulsants, amino glycosides or polypeptide antibiotics) or who were pregnant or breast feeding and those with severe renal, hepatic, metabolic or neuromuscular diseases were not studied. Patients with anticipated difficult intubation (Mallampati score ${ }^{3}$ III and more) were also excluded. A pre-anaesthetic questionnaire was used to collect patients' demographic data - gender, age, weight, height, ASA physical status classification; derived parameters (body mass index, body surface area) were computed ${ }^{4}$.

\section{Anaesthesia}

The patients were premedicated orally with diazepam 5-10 mg $1 \mathrm{hr}$ before the beginning of surgery. On arrival in the operating room, an intravenous cannula was inserted into a forearm vein. Datex-Ohmeda $\mathrm{S} / 5^{\mathrm{TM}}$ Anaesthesia Monitor with relevant modules (ECG, non-invasive blood pressure [NIBP], pulse oxymetry, oxygen inspiratory and exspiratory concentrations, spirometry, core and skin temperature) was used to monitor the patient during anaesthesia and surgery. After 3 min preoxygenation, intravenous premedication with midazolam (Dormicum ${ }^{\circledR}$, F. Hoffmann-LaRoche, $0.05 \mathrm{mg} \mathrm{kg}^{-1}$ ) and sufentanil 
(Sufenta ${ }^{\circledR}$ forte, Janssen Pharmaceutica, $0.1 \mu \mathrm{g} \mathrm{kg}^{-1}$ ) was injected into a rapidly running infusion of normal saline. Total intravenous anaesthesia (TIVA) in TCI mode (target controlled infusion) was induced and maintained with a Base Primea ${ }^{\circledR}$ (Fresenius Vial) infusion device. Target plasmatic concentrations were initially set to $2.0 \mu \mathrm{g} \mathrm{ml}^{-1}$ for propofol (Propofol Abbott, Abbott Laboratories) in Schnider's model ${ }^{5}$ and $1.8 \mathrm{ng} \mathrm{ml}^{-1}$ for sufentanil in Gepts's mode ${ }^{5}$, respectively, and adjusted according to clinical response during anaesthesia. To facilitate tracheal intubation, neuromuscular block was induced with single bolus dose of rocuronium (Esmeron ${ }^{\circledR}$, Organon) $0.6 \mathrm{mg} \mathrm{kg}^{-1}$ injected intravenously during 5 seconds. Following maximal depression of $\mathrm{T}_{1}$ (onset time), direct laryngoscopy was initiated followed by tracheal intubation. The endotracheal tube was connected to closed "low-flow" anaesthetic breathing circuit with a mixture of $40 \%$ oxygen in air; mechanical ventilation was adjusted to maintain end-tidal partial pressure of carbon dioxide $\left(E_{T} C_{2}\right)$ between 4.7 and $5.0 \mathrm{kPa}$. Both oesophageal and skin temperatures were recorded continuously. Thenar skin temperature was monitored using a probe placed on the dorsum of the hand from which the response to ulnar nerve stimulation was recorded. Skin temperature over the thenar muscles was maintained above $34{ }^{\circ} \mathrm{C}$ throughout the study period by wrapping the arm in cotton wool. Sufentanil was discontinued 20 minutes before the end of anaesthesia and tracheal extubation was not performed before full recovery from neuromuscular block (TOF-ratio $\geq 0.90$ ). When required, the recovery was accelerated with neostigmine (Syntostigmin, Hoechst-Biotika, $0.04 \mathrm{mg} \mathrm{kg}^{-1}$ ) given together with atropine (Atropin, Hoechst-Biotika, $0.015 \mathrm{mg} \mathrm{kg}^{-1}$ ).

\section{Neuromuscular monitoring}

Neuromuscular transmission monitoring complied with GCRP (good clinical research practice) $)^{6,7}$, using TOF-Watch ${ }^{\circledR}$ SX (Organon) NMT monitor. After induction, but before administration of the neuromuscular blocking drug, the TOF-Watch ${ }^{\circledR}$ SX NMT monitor was calibrated using its automatic start-up-procedure, and we then applied $0.1 \mathrm{~Hz}$ single twitch stimulation. Following relaxant injection and after maximal neuromuscular block was established, we switched to TOF stimulation assessed at $15 \mathrm{sec}$ intervals by stimulation of ulnar nerve with four rectangular impulses at $2 \mathrm{~Hz}$, duration $0.2 \mathrm{~ms}$ and supramaximal current. The evoked muscle response of adductor pollicis muscle was monitored with accelerometry with a sensor attached to the distal phalanx of the pollex. The forearm was immobilized in supination on a splint and original hand adaptor (Organon) was interposed between pollex and index finger. All data reflecting the effect of neuromuscular blocker (TOF-ratio, $\mathrm{T}_{1}$ ) were transferred into PC via optical cable (Organon). TOFWatch $^{\circledR}$ SX Monitor software v. 2.2 INT (Organon) was used to display the NMT values on the screen and store for further processing.

The first response $\left(T_{1}\right)$ in the TOF stimulation was used as the parameter for pharmacodynamic measure- ments. A spontaneous recovery until $75 \%$ of $\mathrm{T}_{1}$ was allowed and following pharmacodynamic values were determined in all patients:

1. ONSET TIME ( seconds) = time interval from the completion of the intravenous injection of the relaxant to maximal $\mathrm{T}_{1}$ depression

2. CLINICAL DURATION (minutes) = time interval from the completion of the intravenous injection of the relaxant to spontaneous recovery of $\mathrm{T}_{1}$ to $25 \%$ of the control

3. RECOVERY INDEX (minutes) = time interval from the end of clinical duration $\left(\mathrm{T}_{1}=25 \%\right)$ to $75 \%$ recovery of $\mathrm{T}_{1}\left(\mathrm{~T}_{1}=75 \%\right)$

\section{Statistical support}

Statistical calculations were carried out using the software packages InStat v. 3.06 and Prism 4.03 (GraphPad Software, San Diego, California, USA, www.graphpad. com). The sample size was determined by performing a power analysis based on a previous study ${ }^{8}$. From the data, we calculated that 120 patients in each group would be sufficient to find a significant difference of $10 \%$ or more in clinical duration between groups $(0.05$ two-sided significance level $[\alpha=0.05], 80 \%$ power $[\beta=0.2])$. Depending on the character and distribution of the data, comparisons between groups were made by means of Student's unpaired t-test, Mann-Whitney Rank Sum Test and Fisher's exact test. The results are expressed as means (SD - standard deviation) or frequencies; $p$ values equal to or less than 0.05 were considered statistically significant.

\section{RESULTS}

250 patients ( 125 men, 125 women) were initially enrolled in the study. Due to technical difficulties with NMT calibration and unstable reference $T_{1}$ values, 5 patients ( 4 men and 1 woman) had to be excluded resulting in a final size of groups 121 (men) and 124 (women), respectively. The patients' demographics are summarized in Table 1. There were no differences between male and female patients in age and ASA grades. However, men were significantly larger $(p<0.001)$ and heavier $(p<0.05)$ than women, but the body mass index was comparable (ns). The pharmacodynamic data are listed in Table 2. The onset times were shorter and the clinical duration was significantly longer in females $(p<0.0001)$. In recovery index, no differences between males and females could be demonstrated $(n s)$.

\section{DISCUSSION}

The aim of the study was to determine if there was any difference between the sexes in the sensitivity to a standard intubation dose of rocuronium $\left(2 \times \mathrm{ED}_{95}, 0.6 \mathrm{mg} \mathrm{kg}^{-1}\right)$. We used rigorous exclusion criteria and controlled other factors known to interfere with neuromuscular transmis- 
Table 1. Demographic data.

\begin{tabular}{|c|c|c|}
\hline & $\begin{array}{c}\text { men } \\
(n=121)\end{array}$ & $\begin{array}{c}\text { women } \\
(n=124)\end{array}$ \\
\hline Age (years) & $45.7(11.7)$ & $46.4(11.3)$ \\
\hline Weight $(\mathrm{kg})$ & $75.8(11.5)$ & $72.0(12.0)^{*}$ \\
\hline Height $(\mathrm{cm})$ & $172.4(7.7)$ & $167.3(7.6)^{* * *}$ \\
\hline BSA $\left(\mathrm{m}^{2}\right)$ & $1.90(0.16)$ & $1.82(0.18)^{* *}$ \\
\hline BMI $\left(\mathrm{kg} \mathrm{m}^{-2}\right)$ & $26.14(3.46)$ & $25.69(3.74)$ \\
\hline ASA grade $(\mathrm{I} / \mathrm{II})$ & $43 / 78$ & $33 / 91$ \\
\hline
\end{tabular}

Data are means (SD - standard deviation) or frequencies ${ }^{*} \mathrm{p}<0.05,{ }^{* * \mathrm{p}}<0.001,{ }^{* * *} \mathrm{p}<0.0001$

Table 2. Pharmacodynamic parameters.

\begin{tabular}{|l|c|c|}
\hline & $\begin{array}{c}\text { men } \\
(n=121)\end{array}$ & $\begin{array}{c}\text { women } \\
(n=124)\end{array}$ \\
\hline ONSET TIME (seconds) & $104.7(12.2)$ & $92.5(14.2)^{* * *}$ \\
\hline CLINICAL DURATION (minutes) & $31.3(5.5)$ & $43.1(7.9) * * *$ \\
\hline RECOVERY INDEX (minutes) & $14.8(4.0)$ & $14.7(5.0)$ \\
\hline
\end{tabular}

Data are means (SD - standard deviation), ${ }^{* *} \mathrm{p}<0.0001$

sion. In all patients, the depth of anaesthesia was computer-controlled (TCI, TIVA) with identical target level of respective anaesthetic agents (propofol, sufentanil). Total intravenous anaesthesia was preferred to inhalation anaesthesia; our goal was to eliminate the influence of a volatile agent on the depth of muscle relaxation. Only one person (MA) was responsible for the anaesthetic management of all cases and standardized technique was used for neuromuscular monitoring throughout the study.

Until now, the gender aspect in pharmacokinetics and pharmacodynamics of anaesthetic drugs has attracted little attention. However, ongoing research in order to further optimize treatment in anaesthesia shows that gender should be taken into account as a factor that may be predictive for the dosage of several anaesthetic drugs ${ }^{1}$. There is increasing evidence for gender differences in the pharmacokinetics and pharmacodynamics of anaesthetic drugs and neuromuscular blocking agents ${ }^{1,9}$. Females have 20-30\% greater sensitivity to the effects of aminosteroid muscle relaxants ${ }^{10}$. When rapid onset or short duration of action is very important, gender-modified dosing may be considered. Males are more sensitive than females to propofol. It may therefore be necessary to decrease the propofol dose by $30-40 \%$ in males compared with females in order to achieve similar recovery times ${ }^{1}$. Females are more sensitive than males to opioid receptor agonists, as shown for morphine as well as for a number of kappa receptor agonists. On this basis, males will be expected to require $30-40 \%$ higher doses of opioid analgesics than females to achieve similar pain relief ${ }^{1}$. On the other hand, females may experience respiratory depression more often and other adverse effects more easily if they are given the same opioid doses as males. Though not associated with adverse clinical consequences for the patient's outcome, the incidence and the degree of pain and withdrawal reactions in response to the injection of rocuronium is significantly higher in women than in $\operatorname{men}^{11}$. The same implies for precurarization dose of rocuronium ${ }^{12}$.

Our results showed that women were significantly more sensitive to rocuronium than men. The onset times were decreased [92.5 (SD 14.2) vs. 104.7 (SD 12.2) s, respectively; $p<0.0001]$ and the clinical duration was longer [43.1 (SD 7.9) vs. 31.3 (SD 5.5) min, respectively; $p<0.0001]$ in women. Studying rocuronium-induced block after $0.45 \mathrm{mg} \mathrm{kg}^{-1}$, Mencke et al. ${ }^{10}$ demonstrated slower onset by $26 \%$ and shorter clinical duration by 35 $\%$ in men. Xue et al. ${ }^{13}$ showed that the dose-response curve of rocuronium in the men was shifted to the right, indicating a decrease in the sensitivity to rocuronium-induced neuromuscular block versus the women. After an intravenous administration of total dose of $0.4 \mathrm{mg} \mathrm{kg}^{-1}$ rocuronium, neuromuscular block was significantly longer in the women than in the men [clinical duration 18.5 (SD 5.3) vs. 12.5 (SD 4.9) min]. To mimic the typical course of neuromuscular block following relaxant injection, we used the most usual dose of rocuronium $\left(2 \times \mathrm{ED}_{95}, 0.6 \mathrm{mg} \mathrm{kg}^{-1}\right)$ 
that is larger than the doses used in the above-mentioned studies. From the data, we hypothesize that the lower difference in onset times in our study is due to larger dose of rocuronium administered, resulting in more uniformity and less scatter in onset times.

Vecuronium is a nondepolarizer most widely studied for gender differences in its effect. Following administration of $0.1 \mathrm{mg} \mathrm{kg}^{-1}$ vecuronium, male patients had significantly less satisfactory intubation conditions at $60 \mathrm{~s}$ than female patients. It was suggested that differences in response to vecuronium could be explained by differences in distribution volume and muscle mass between sexes ${ }^{14}$. In another study, Xue et al. ${ }^{15}$ found that, compared to women, after intravenous administration, men had lower plasma concentrations of vecuronium and a larger volume of distribution of vecuronium. The pharmacokinetic differences may be related to the differences in the sensitivity to vecuronium between genders. Semple et al. ${ }^{16}$ demonstrated that females were significantly more sensitive to vecuronium than males, requiring $22 \%$ less drug to achieve the same degree of neuromuscular block.

In our study, no difference in recovery index could be demonstrated between men and women. In other words, when the muscle strength recovered to $25 \%$, the further course and subsiding of the block was fairly uniform both in men and women ${ }^{8,17,18}$.

What is the implication for clinical anaesthesia? The easiness of intravenous injection of muscle relaxant, resulting in neuromuscular block, contrasts with the potential clinically serious consequences following its application and with considerable interindividual variability of effect. Particularly at the end of anaesthesia, this may present a problem; in one patient, the effect of a single bolus dose of NMBA may have fully subsided, while in the other one, there is a significant degree of block still present ${ }^{8,19-22}$. This variability of action may be further accentuated by gender differences. Alkhazrajy et al. ${ }^{23}$ assessed the residual muscle weakness after general anaesthesia either without muscle relaxant or with rocuronium or vecuronium, respectively. They compared handgrip strength preoperatively and one hour postoperatively with hand dynamometer. The degree of weakness for the relaxant groups was unrelated to age but was strongly influenced by the patient's sex. One hour postoperatively, female patients showed a marked decrease in handgrip strength after both vecuronium and rocuronium ( $32 \%$ and $34 \%$, respectively). These results suggest that female patients are more likely to have residual weakness after anaesthesia with muscle relaxants and therefore may be more predisposed to postoperative pulmonary complications ${ }^{24}$. This constitutes evidence that patient undergoing surgery benefit from perioperative neuromuscular monitoring ${ }^{22}$.

\section{CONCLUSION}

This study confirmed the gender differences in the myorelaxant effect of $0.6 \mathrm{mg} \mathrm{kg}^{-1}$ rocuronium. Under the conditions described, women were more sensitive to rocuronium than men. The onset times were shorter by
$12 \%$ and the clinical duration was prolonged by $38 \%$. The recovery index was not influenced by gender.

This suggests that the routine dose of rocuronium should be reduced in women compared with men.

\section{ACKNOWLEDGEMENT}

This study was supported by the Czech Ministry of Health Internal Grant Agency - project ND7665-3/2003. The authors express their sincere thanks to Josef Zakravsky (Hoyer, Prague, Czech Republic), Juraj Gasperik (Organon, Slovakia) and Vladimir Srek (Fresenius Medical Care, Czech Republic) for technical assistance.

\section{REFERENCES}

1. Pleym H, Spigset O, Kharasch ED, Dale O. Gender differences in drug effects: implications for anesthesiologists. Acta Anaesthesiol Scand 2003; 47:241-59.

2. Herold I. Muscle relaxants in anaesthesiology and intensive care medicine (in Czech). $1^{\text {st }}$ edition. Praha: Maxdorf; 2004.

3. Mallampati SR, Gatt SP, Gugino LD, Desai SP, Waraksa B, Freiberger D, Liu PL. A clinical sign to predict difficult tracheal intubation: a prospective study. Can Anaesth Soc J 1985; 32:429-34

4. References and formulas used by the Body Surface Area Calculator. Formula for Body Mass Index. Formulas for Body Surface Area [on line, cited 2007 Feb 15]. Available from http://www.halls.md/bodysurface-area/refs.htm.

5. Servin F, Cazalaa JB, Levron JC. Propofol, Sufentanil, Remifentanil in TCI. Bibliographical study of anesthetic agents used in the Base Primea $^{\circledR}$, Fresenius Vial. Le Grand Chemin, Brezins (France): Fresenius Vial, 2003.

6. Fuchs-Buder T, Claudius C, Skovgaard LT, Eriksson LI, Mirakhur RK, Viby-Mogensen J. Good clinical research practice in pharmacodynamic studies of neuromuscular blocking agents II: the Stockholm revision. Acta Anaesthesiol Scand 2007; 51:789-808.

7. Viby-Mogensen J, Ostergaard D, Donati F, Fisher D, Hunter J, Kampmann JP. Pharmacokinetic studies of neuromuscular blocking agents: Good Clinical Research Practice (GCRP). Acta Anaesthesiol Scand 2000; 44:1169-90.

8. Adamus M, Belohlavek R, Koutna J, Vujcikova M, Janaskova E. Cisatracurium vs. rocuronium: a prospective, comparative, randomized study in adult patients under total intravenous anaesthesia. Biomed Pap Med Fac Univ Palacky Olomouc Czech Repub 2006; 150(2):333-8.

9. Mencke T, Schreiber JU, Knoll H, Werth M, Grundmann U, Rensing H. Influence of gender on the intubation conditions with rocuronium. Anaesthesist 2005; 54:884-8.

10. Mencke T, Soltesz S, Grundmann U, Bauer M, Schlaich N, Larsen R, Fuchs-Buder T. Time course of neuromuscular blockade after rocuronium. A comparison between women and men. Anaesthesist 2000; 49:609-12.

11. Mencke T, Beerhalter U, Fuchs-Buder T. Spontaneous movements, local reactions and pain on injection of rocuronium. A comparison between female and male patients. Acta Anaesthesiol Scand 2001; 45:1002-5.

12. Mencke T, Schreiber JU, Knoll H, Stracke C, Kleinschmidt S, Rensing H, Silomon M. Women report more pain on injection of a precurarization dose of rocuronium: a randomized, prospective, placebo-controlled trial. Acta Anaesthesiol Scand 2004; 48:1245-8.

13. Xue FS, Tong SY, Liao X, Liu JH, An G, Luo LK. Dose-response and time course of effect of rocuronium in male and female anesthetized patients. Anesth Analg 1997; 85:667-71.

14. Houghton IT, Aun CS, Oh TE. Vecuronium: an anthropometric comparison. Anaesthesia 1992; 47:741-6. 
15. Xue FS, An G, Liao X, Zou Q, Luo LK. The pharmacokinetics of vecuronium in male and female patients. Anesth Analg 1998; 86:1322-7.

16. Semple P, Hope DA, Clyburn P, Rodbert A. Relative potency of vecuronium in male and female patients in Britain and Australia. Br J Anaesth 1994; 72:190-4.

17. Melloni C, Devivo P, Launo C, Mastronardi P, Novelli GP, Romano E. Cisatracurium versus vecuronium: a comparative, double blind, randomized, multicenter study in adult patients under propofol/ fentanyl/ $\mathrm{N}_{2} \mathrm{O}$ anesthesia. Minerva Anestesiol 2006; 72:299-308.

18. Hans P, Welter P, Dewandre PY, Brichant JF, Bonhomme V. Recovery from neuromuscular block after an intubation dose of cisatracurium and rocuronium in lumbar disc surgery. Acta Anaesthesiol Belg 2004; 55:129-33.

19. Baillard C, Gehan G, Reboul-Marty J, Larmignat P, Samama CM, Cupa M. Residual curarization in the recovery room after vecuronium. Br J Anaesth 2000; 84:394-5.
20. Cammu G, de Baerdemaeker L, den Blauwen N, de Mey JC, Struys M, Mortier E. Postoperative residual curarization with cisatracurium and rocuronium infusions. Eur J Anaesthesiol 2002; 19:129-34

21. Beaussier M, Boughaba MA. Residual neuromuscular blockade Ann Fr Anesth Reanim 2005; 24:1266-74.

22. Viby-Mogensen J. Postoperative residual curarization and evidencebased anaesthesia. Br J Anaesth 2000; 84:301-3.

23. Alkhazrajy W, Khorasanee AD, Russell WJ. Muscle weakness after muscle relaxants: an audit of clinical practice. Anaesth Intensive Care 2004; 32:256-9.

24. Berg H, Roed J, Viby-Mogensen J, Mortensen CR, Engbaek J, Skovgaard LT, Kristel JJ. Residual neuromuscular block is a risk factor for postoperative pulmonary complications. A prospective, randomised, and blinded study of postoperative pulmonary complications after atracurium, vecuronium and pancuronium. Acta Anaesthesiol Scand 1997; 41:1095-103. 